


\title{
ON A CHARACTERIZATION OF INFINITE COMPLEX MATRICES MAPPING THE SPACE OF ANALYTIC SEQUENCES INTO ITSELF
}

\author{
LOUISE A. RAPHAEL
}

Let $S$ be the space of all complex sequences. An element $u=\left\{u_{n}\right\}_{n=0}^{\infty}$ of $S$ is called analytic if for some constant $M>0$, $\left|u_{n}\right| \leqq M^{n+1}$ for $n=0,1,2, \cdots$. By $A$ denote the space of all analytic sequences. Clearly $A$ is the space of all complex functions analytic at zero. 1. Heller has proved

Theorem 1. The transformation $y_{n}=\sum_{m=0}^{\infty} c_{n m} u_{m}$ maps $A$ into $A$ if and only if for every $p>0$ there exists a $q>0$ and a constant $M>0$ such that $\left|c_{n m}\right| \leqq M p^{m} / q^{n}$ for $m, n=$ $0,1,2, \cdots$; and also if and only if the function $G$ of two complex variables (i.e., in $E \times E$, where $E$ is the complex plane) respresented by the double power series $G(z, y)=\sum_{m, n=0}^{\infty} c_{n m} z^{m} y^{n}$ be regular on $E \times 0$.

The present paper provides an alternative proof for the theorem in order to give insight into the structure of $A$ as a countable union of $B K$ spaces, that is, Banach spaces with coutinuous coordinates.

Let $q>0$ be fixed and $A_{q}=\left\{u \in S\left|\sup _{n}\right| q^{n} u_{n} \mid=\|u\|_{q}<\infty, n=\right.$ $0,1,2, \cdots\}$.

Theorem 2. (1) $A=\bigcup_{n=0}^{\infty} A_{q_{n}}$ where $q_{n} \downarrow 0$, and

(2) for any $q>0,\left(A_{q},\|u\|_{q}\right)$ is a $B K$ space.

Proof. (1) A complex sequence $u=\left\{u_{n}\right\}_{n=0}^{\infty}$ is analytic if and only if the $\sup _{n}\left|q^{n} u_{n}\right| \leqq M$ for some $q>0$, some constant $M>0$ and $n=0,1,2, \cdots$. It now follows that $A=\mathrm{U}_{0<q<\infty} A_{q}$. The proof is completed by a set theoretic argument showing that $\mathrm{U}_{0<q<\infty} A_{q}=$ $\bigcup_{n=0}^{\infty} A_{q_{n}}$ after observing that if $0<r<s$, then $A_{s} \subset A_{r}$.

(2) It suffices to observe that $\left(A_{q},\|u\|_{q}\right)$ is isometrically isomorphic with the Banach space of all bounded complex sequences

$$
(m)=\left\{u \in S\left|\|u\|_{(m)}=\sup _{n}\right| u_{n} \mid\right\} .
$$

The operator $E_{q}$ from $A_{q}$ into $(m)$ establishing this isomorphism is defined by $E_{q}:\left\{u_{n}\right\}_{n=0}^{\infty} \rightarrow\left\{q^{n} u_{n}\right\}_{n=0}^{\infty}$. Finally for each $n,\left|u_{n}\right| \leqq\|u\|_{q} / q^{n}$. Thus the coordinate functional $P_{n}(u)=u_{n}$ is continuous, being a linear operator on $A_{q}$. This proves that the space $\left(A_{q},\|u\|_{q}\right)$ is a $B K$ space.

By a mapping $C$ of a sequence space $X$ into a sequence space $Y$ generated by an infinite complex matrix $\left(c_{n m}\right) m, n=0,1,2, \cdots$ is 
meant $(y=C(u), u \in X)$ if and only if $\left(y_{n}=\sum_{m=0}^{\infty} c_{n m} u_{m}, y=\left\{y_{n}\right\}_{n=0}^{\infty} \in Y\right)$.

Theorem 3. Let $C$ be the transformation from $A$ into $A$ generated by an infinite complex matrix $\left(c_{n m}\right) n, m=0,1,2, \cdots$. For each $p>0$ and $q>0$ fixed let $A_{p q}=\left\{u \in A_{p} \mid C(u) \in A_{q}\right\}$. Then

(1) $A_{p}=\bigcup_{n=0}^{\infty} A_{p q_{n}}$ where $q_{n} \downarrow 0$, and

(2) for each $p>0$ and $q>0$ fixed,

$$
\left(A_{p q},\|u\|_{p q}=\|u\|_{p}+\|C(u)\|_{q}\right)
$$

is a BK space.

Proof. (1)

$$
\begin{aligned}
A_{p} & =\left\{u \in A_{p} \mid C(u) \in A=\bigcup_{n=0}^{\infty} A_{q_{n}}, q_{n} \downarrow 0\right\} \\
& =\bigcup_{n=0}^{\infty}\left\{u \in A_{p} \mid C(u) \in A_{q_{n}}\right\}=\bigcup_{n=0}^{\infty} A_{p q_{n}} .
\end{aligned}
$$

(2) For each $u=\left\{u_{n}\right\}_{n=0}^{\infty}$ belonging to the $B K$ space $A_{p},(C(u))_{k}=$ $C_{k}(u)=\sum_{n=0}^{\infty} c_{k n} u_{n}$ on $A_{p}$ is the limit of the sequence of continuous linear operators $\sum_{n=0}^{j} c_{k n} u_{n} j=0,1,2, \cdots$ on $A_{p}$. So $C_{k}$ is a continuous linear operator on $A_{p}$ for each $k=0,1,2, \cdots$ by [2, Th. 17, p. 54]. This shows that $C$ is a continuous linear operator from $A_{p}$ into $A$.

The $B K$ spaces $\left(A_{p},\|u\|_{p}\right),\left(A_{q},\|u\|_{q}\right)$ and the continuous linear map $C: A_{p} \rightarrow A$ satisfy the conditions of [4, Th. 1, p. 226]. This together with [4, Th. 3, p. 205] prove that $A_{p} \cap C^{-1}\left(A_{q}\right)=A_{p q}$ is a $F K$ space (Frechet space with continuous coordinates) with the norm $\|u\|_{p}+\|C(u)\|_{q}$ (as the sup of two normed topologies is given by the sum of the norms). That $\left(A_{p q},\|u\|_{p q}\right)$ is a $B K$ space is now immediate.

THEOREM 4. Let $C$ be the transformation from $A$ into $A$ generated by an infinite complex matrix $\left(c_{n m}\right) n, m=0,1,2, \cdots$. Then

(1) for every $p>0$ there exists a $q>0$ such that $C$ maps $A_{p}$ into $A_{q}$.

The transformation $C$ from $A_{p}$ into $A_{q}$ generated by $\left(c_{n m}\right)$ for fixed $p>0$ and $q>0$

(2) is linear and continuous, and

(3) its norm, $\|C\|=\sup _{n} \sum_{m=0}^{\infty} q^{n}\left|c_{n m}\right| p^{-m}, n=0,1,2, \cdots$.

Proof. (1) For any $p>0, C: A_{p} \rightarrow A=\bigcup_{n=0}^{\infty} A_{q_{n}}, q_{n} \downarrow 0$. Moreover $A_{p}=\bigcup_{n=0}^{\infty} A_{p q_{n}}$. And by defintion of the Banach norm $\|u\|_{p q}=$ $\|u\|_{p}+\|C(u)\|_{q}$ on $A_{p q}$, the injective maps from $A_{p q_{n}}$ into $A_{p}$ are 
continuous for any $p>0$. Thus by [4, Corollary 6, p. 205] or [5, Satz 4.6, p. 472], there exists an index $k$ such that $A_{p}=A_{p q_{k}}$. This $q_{k}$ is the desired $q$.

(2) The lineary of $C$ is clear. Continuity follows from [4, Corollary 5, p. 204].

(3) Map $A_{p}$ into $(m)$ by the operator $E_{p}: u=\left\{u_{m}\right\}_{m=0}^{\infty} \rightarrow\left\{p^{m} u_{m}\right\}_{m=0}^{\infty}$. Define the operator $B$ to be $E_{q} C E_{p}^{-1}$. Clearly $B$ is an operator from $(m)$ into $(m)$ which is generated by the infinite matrix

$$
\left(b_{n m}\right)=\left(q^{n} c_{n m} p^{-m}\right) \text {. }
$$

And so $B$ is linear and continuous from $(m)$ into $(m)$ and $\|B\|=$ $\sup _{n} \sum_{m=0}^{\infty} q^{n}\left|c_{n m}\right| p^{-m} n=0,1,2, \cdots$. But $\|C\|=\|B\|$.

Proof of Theorem 1. By Theorem 4 (1) and (3) for every $p>0$ there exists a $q>0$ such that $C$ maps $A_{p}$ into $A_{q}$ and

$$
C \|=\sup _{n} \sum_{m=0}^{\infty} q^{n}\left|c_{n m}\right| p^{-m} \leqq M, n=0,1,2, \cdots
$$

respectively. Thus $\left|c_{n m}\right| \leqq M p^{m} / q^{n}, m, n=0,1,2, \cdots$ This proves necessity.

Since $A=\bigcup_{0<p<\infty} A_{p}$, it suffices to show that the operator $C$ is well defined on $A_{p}$. Let $0<r<1$. For the number $p r$ there exists a number $q>0$ such that $\left|c_{n m}\right| \leqq M(p r)^{m} q^{-n}$ for all $m$ and $n$ and some $M$, and so $\left|c_{n m} u_{m}\right| \leqq M r^{m} q^{-n}\|u\|_{p}$ for all $m$ and $n$. This implies that the series $\sum_{m=0}^{\infty} c_{n m} u_{m}$ is convergent and

$$
\left|\sum_{m=0}^{\infty} c_{m n} u_{m}\right| \leqq M(1-r)^{-1} q^{-n}\|u\|_{p} .
$$

Thus the sequence $y=C(u)$ belongs to the space $A_{q}$ and therefore also to the space $A$. This proves the sufficiency of the condition.

The functional analysis method employed herein has implications beyond the proof of Theorem 1. It enables us to extend Heller's result to the space of Borel measurable functions bounded with respect to a weight function. This will be the subject of a forthcoming paper.

It is a pleasure to thank Professors W. Bogdanowicz, I. Heller and the referee for their critical readings and valuable suggestions.

\section{BIBLIOGRAPHY}

1. S. Banach, Theorie des operation lineaires, Monografje Matenatyczne, Warsaw, 1932 .

2. N. Dunford and J. Schwartz, linear operators, I, Interscience, New York, 1964. 
3. I. Heller, Contributions to the theory of divergent series, Pacific J. Math 2 (1952), 153-177.

4. A. Wilansky, Functional analysis, Blaisdell, New York, 1964.

5. K. Zeller, Allgemeine eigenschaften von limiterungsverfahren, Math. Zeitsch. 53 (1951), 463-487.

Received August 11, 1967. Research was sponsored by the Office of Naval Research (Nonr-4311(00)).

CATHOLIC UNIVERSITY AND

HOWARD UNIVERSITY 


\section{PACIFIC JOURNAL OF MATHEMATICS}

EDITORS

H. ROYDEN

Stanford University

Stanford, California

R. R. Phelps

University of Washington

Seattle, Washington 98105
J. DugundJI

Department of Mathematics

University of Southern California

Los Angeles, California 90007

\section{RICHARD ARENS}

University of California

Los Angeles, California 90024

\section{ASSOCIATE EDITORS}
E. F. BeCKENBACH
B. H. NeUmanN
F. WOLF
K. YOSIDA

\section{SUPPORTING INSTITUTIONS}

UNIVERSITY OF BRITISH COLUMBIA CALIFORNIA INSTITUTE OF TECHNOLOGY UNIVERSITY OF CALIFORNIA MONTANA STATE UNIVERSITY UNIVERSITY OF NEVADA NEW MEXICO STATE UNIVERSITY OREGON STATE UNIVERSITY UNIVERSITY OF OREGON OSAKA UNIVERSITY UNIVERSITY OF SOUTHERN CALIFORNIA
STANFORD UNIVERSITY UNIVERSITY OF TOKYO UNIVERSITY OF UTAH WASHINGTON STATE UNIVERSITY UNIVERSITY OF WASHINGTON

AMERICAN MATHEMATICAL SOCIETY CHEVRON RESEARCH CORPORATION TRW SYSTEMS NAVAL WEAPONS CENTER 


\section{Pacific Journal of Mathematics \\ Vol. 27, No. $1 \quad$ January, 1968}

Willard Ellis Baxter, On rings with proper involution ............... 1

Donald John Charles Bures, Tensor products of $W^{*}$-algebras........... 13

James Calvert, Integral inequalities involving second order derivatives . . . . 39

Edward Dewey Davis, Further remarks on ideals of the principal class.... 49

Le Baron O. Ferguson, Uniform approximation by polynomials with integral

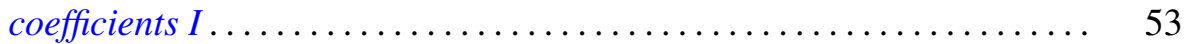

Francis James Flanigan, Algebraic geography: Varieties of structure

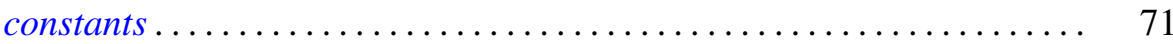

Denis Ragan Floyd, On QF -1 algebras ..................... 81

David Scott Geiger, Closed systems of functions and predicates ......... 95

Delma Joseph Hebert, Jr. and Howard E. Lacey, On supports of regular Borel measures ................................... 101

Martin Edward Price, On the variation of the Bernstein polynomials of a function of unbounded variation ........................ 119

Louise Arakelian Raphael, On a characterization of infinite complex matrices mapping the space of analytic sequences into itself........ 123

Louis Jackson Ratliff, Jr., A characterization of analytically unramified

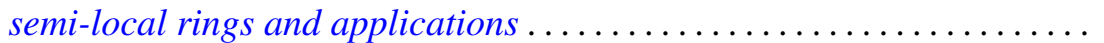

S. A. E. Sherif, A Tauberian relation between the Borel and the Lototsky transforms of series ................................ 145

Robert C. Sine, Geometric theory of a single Markov operator .......... 155

Armond E. Spencer, Maximal nonnormal chains in finite groups......... 167

Li Pi Su, Algebraic properties of certain rings of continuous functions .... 175

G. P. Szegô, A theorem of Rolle's type in $E^{n}$ for functions of the class $C^{1} \ldots 193$

Giovanni Viglino, A co-topological application to minimal spaces ........ 197

B. R. Wenner, Dimension on boundaries of $\varepsilon$-spheres ............... 201 